\title{
Lemierre's Syndrome with Paradoxical Emboli
}

\author{
Ahmed Aljohaney and Anne McCarthy
}

\begin{abstract}
Lemierre's syndrome is a rare anaerobic oropharyngeal infection complicated by internal jugular thrombosis, the predominant etiology is Fusobacterium necrophorum. Septic emboli to lungs and distant organs have been described, however, to date there have been no published cases associated with embolization across a patent foramen ovale. We describe a case of Lemierre's syndrome with septic arterial emboli resulting in multiple cerebral abscesses and cutaneous manifestations. The outcome was favorable with appropriate antimicrobial therapy.
\end{abstract}

Key words: Lemierre's, patent foramen ovale, Fusobacterium necrophorum, brain abscess, emboli

(Inter Med 49: 1433-1436, 2010)

(DOI: 10.2169/internalmedicine.49.3263)

\section{Introduction}

Though the syndrome was initially described by Cade and then Schottmuller (1) in the early 1900s, it was Dr. Andre Lemierre in 1936 who described 20 cases of anaerobic septicaemia from internal jugular thrombosis associated with head and neck infection and septic emboli (1); 18 of these individuals died. In the1960s and 1970s, when penicillin was frequently used to treat pharyngeal infections, it became known as the "forgotten disease" (2). There has been a recent a re-emergence of this syndrome, likely related to increased clinician awareness and decreased antimicrobial use to treat upper respiratory tract complaints (2).

We report the first adult case in literature of Lemierre's syndrome (LS) with paradoxical emboli across a patent foramen ovale resulting in multiple bilateral brain abscesses and lower limb septic emboli.

\section{Case Report}

A 20-year-old woman was well until two weeks prior to presentation. She developed a sore throat for which she did not seek medical attention; 7 days later she had a sudden onset of left sided pleuritic chest pain, cough and fever. She then sought medical attention and had a chest $\mathrm{X}$ ray at a community hospital, was diagnosed with community acquired pneumonia and treated with a seven-day course of azithromycin. She continued to feel unwell with intermittent fever and presented to our hospital with a 1-day history of right foot pain and rash, 14 days after the onset of illness. Her past history was unremarkable except for two episodes of acute pancreatitis of unclear etiology.

On admission, physical examination she was toxic appearing with blood pressure of 70/40 $\mathrm{mmHg}$, pulse $140 \mathrm{bpm}$, respiratory rate 24 , and temperature $38.3^{\circ} \mathrm{C}$. Her oxygen saturation was $98 \%$ breathing room air. She had enlarged tonsils but otherwise a normal oropharyngeal examination. There was no neck tenderness, adenopathy or venous swelling in the vicinity of the jugular vein. Her respiratory exam demonstrated bronchial breath sounds and dullness to percussion over the left lower lobe. Multiple painful palpable purpuric lesions were noted on the plantar surface of her right foot. There were no cardiac murmurs or subungual hemorrhages and the neurological examination was completely normal.

Laboratory analysis revealed a white blood cell count of 20,000 with $77.4 \%$ neutrophils with toxic granulations, $17 \%$ bands, $4 \%$ lymphocytes, and $1 \%$ monocytes. Liver enzymes were slightly elevated, creatinine was normal and the urine microscopy showed trace blood but no casts. Chest radiograph revealed right upper and left lower lobar consolidations.

A right internal jugular triple lumen catheter was inserted and the patient was admitted to the critical care unit with a diagnosis of pneumonia and septic shock. She received fluid 


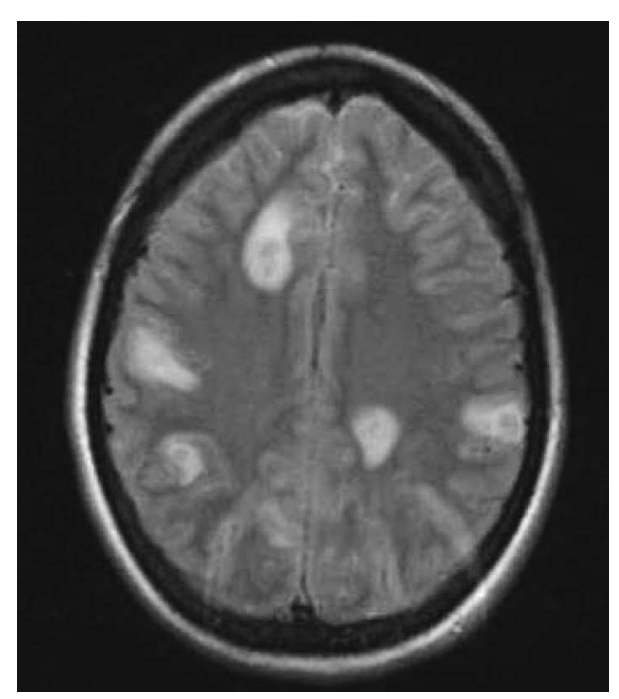

Figure 1. Magnetic resonance imaging of the brain showing multiple bilateral ring-enhancing lesions demonstrating restricted diffusion consistent with Abscesses/Septic emboli.

resuscitation and intravenous cefotaxime, vancomycin and gentamicin pending culture results. On the second hospital day, she developed acute headache, neck pain and photophobia. Lumbar puncture was performed and the cerebrospinal fluid contained $398 \mathrm{WBCs}\left(10^{6} / \mathrm{L}\right)(73 \%$ neutrophils), total protein of $0.46 \mathrm{~g} / \mathrm{L}$ (normal 0.15-0.45) and glucose of 2 $\mathrm{mmoL} / \mathrm{L}$ (normal 2.2-3.9). An MRI of her head showed multiple (more than 20) brain abscesses, the largest measuring $2.3 \times 1.5 \mathrm{~cm}$ (Fig. 1). Chest CT revealed lingular and right upper lobe cavitary lung lesions with bilateral pleural effusions (Fig. 2). Blood cultures drawn on admission grew Fusobacterium necorphorum, suggesting a diagnosis of LS. Her antibiotics were adjusted to intravenous penicillin and metronidazole and the triple lumen catheter was removed. Doppler ultrasonogarphy of the neck revealed a nonocclusive clot in the right internal jugular vein and a CT neck confirmed enlarged palatine tonsils and mild cervical lymph node enlargement.

Due to evidence of venous and arterial lesions, a patent foramen ovale (PFO) was suspected. Initial transesophageal echocardiogram was negative for both PFO and valvular vegetation; however probe-patent foramen ovale was confirmed by contrast echocardiography with positive bubble study. Skin biopsy showed leukocytoclastic vasculitis with micro thrombi consistent with septic emboli and skin biopsy culture grew fusobacterium. Therefore the patient was diagnosed with LS with paradoxical septic emboli across the patent foramen ovale. She improved on the antibiotics and was discharged home in a good state of health, with eventual complete clinical and radiological recovery.

\section{Discussion}

LS characteristically occurs in previously healthy teenagers and young adults, but can also affect other age groups (3). It involves internal jugular thrombosis caused by
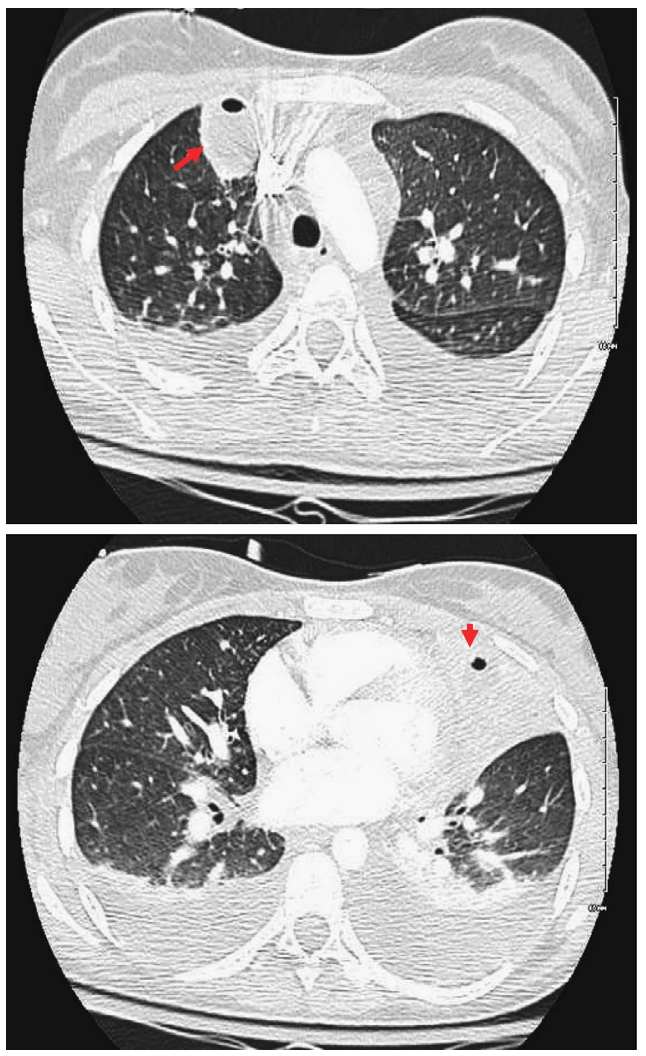

Figure 2. Computed Tomography (CT) of theThorax showing bilateral Cavitary lung lesions with associated air fluid level (Arrows) involving Right upper lobe (left) and lingula (right) with bilateral pleural effusions.

anaerobic suppurative oropharyngeal infection and results in secondary metastatic foci. The predominant causative organism is $F$. necrophorum, occurring in about $81.7 \%$ of cases (4). This organism is a commensal in the oropharynx and does not usually penetrate the mucosal surface except in the setting of an altered host-defense mechanism, such as a bacterial or viral pharyngitis, leading to alteration of the pharyngeal mucosa (2). Following primary infection in the oropharynx, internal jugular vein thrombophlebitis develops either from direct extension through the facial plane between the tonsils and the parapharyngeal space or by hematogenous or lymphatic spread from peritonsillar vessels (5). Subsequently septic emboli arise and spread to distant organs. Untreated LS is associated with a mortality ranging from 4$18 \%$ (2).

Pulmonary involvement occurs in the majority (79.8\%) of cases (4). Nodular infiltrates and pleural effusions are the most common metastatic presentations (3). Empyema, pneumothoraces and pneumatoceles have also been described (4) and rarely patients develop respiratory failure with ARDS requiring ventilation (6). The second most common metastatic presentation includes septic arthritis of the large joints, mainly shoulders, knees and hips, occurring in $16.5 \%$ (6).

Central nervous system involvement is very rarely reported (Table 1). Meningitis and encephalopathy have been described in children (7-10) and there have been occasional reports of cranial nerve palsies $(7,11,12)$. Possible mecha- 
Table 1. Clinical Features of Reported Cases of Lemierre Syndrome with Central Nervous System Involvement

\begin{tabular}{|c|c|c|c|c|c|c|c|}
\hline $\begin{array}{l}\text { Reference/ } \\
\text { Year of } \\
\text { publication }\end{array}$ & Sex/Age & $\begin{array}{l}\text { Neurological } \\
\text { involvement }\end{array}$ & $\begin{array}{c}\text { Neck symptoms/ } \\
\text { Tonsillar } \\
\text { enlargement }\end{array}$ & $\begin{array}{c}\text { Blood cultures } \\
\text { grew } \\
\text { F. necrophorum }\end{array}$ & $\begin{array}{c}\text { CSF Cultures } \\
\text { grew } \\
\text { F. necrophorum }\end{array}$ & $\begin{array}{l}\text { Antibiotics } \\
\text { given }\end{array}$ & Outcome \\
\hline (14)/1978 & F/8ys. & Brain Abscess & NR & NR & $\mathrm{NR}^{*}$ & Penicillin & Recovered \\
\hline$(10) / 1980$ & M/12ys. & Encephalopathy & Yes & Yes & No & $\begin{array}{l}\text { Penicillin G and } \\
\text { chloramphenicol }\end{array}$ & Recovered \\
\hline (7)/1989 & M/6 weeks & Meningitis & No & Yes & Yes & Metronidazole & Died \\
\hline (7)/1989 & $\mathrm{M} / \mathrm{NR}$ & Meningitis & No & Yes & Yes & Metronidazole & Recovered \\
\hline (7)/1989 & M/5ys. & Meningism & No & Yes & NR & Metronidazole & Recovered \\
\hline (7)/1989 & F/14ys. & $\begin{array}{l}\text { Meningitis, } \\
\text { papilloedema and } \\
\text { cranial nerve } \\
\text { palsies }\end{array}$ & No & Yes & No & $\begin{array}{l}\text { Cefotaxime and } \\
\text { Metronidazole }\end{array}$ & Recovered \\
\hline (7)/1989 & NR & $\begin{array}{l}\text { Meningitis and } \\
\text { cavernous sinus } \\
\text { thrombus }\end{array}$ & Yes & Yes & NR & Metronidazole & Recovered \\
\hline (7)/1989 & NR & $\begin{array}{l}\text { Multiple brain } \\
\text { abscesses }\end{array}$ & Yes & Yes & NR & Metronidazole & Recovered \\
\hline (7)/1989 & NR & Meningism & Yes & Yes & No & Metronidazole & Recovered \\
\hline$(15) / 1990$ & M/17ys. & 3 Brain abscesses & Yes & Yes & NR & Penicillin G & Recovered \\
\hline$(16) / 1993$ & F/6ys. & $\begin{array}{c}\text { Unilateral Brain } \\
\text { Abscesses }\end{array}$ & Yes & Yes & NR & $\begin{array}{l}\text { Penicillin G and } \\
\text { Metronidazole }\end{array}$ & Recovered \\
\hline (8)/1994 & M/5ys. & $\begin{array}{l}\text { Meningitis and } \\
\text { Transverse sinus } \\
\text { thrombosis }\end{array}$ & No & Yes & Yes & $\begin{array}{l}\text { Cefotaxime and } \\
\text { Metronidazole }\end{array}$ & Recovered \\
\hline (9)/1997 & M/9 mo. & $\begin{array}{l}\text { Meningitis and } \\
\text { Ischemic stroke }\end{array}$ & NR & NR & Yes & $\begin{array}{l}\text { Cefotaxime and } \\
\text { Penicillin }\end{array}$ & Died \\
\hline \multirow{2}{*}{$\begin{array}{l}(17) / 1997 \\
(11) / 2000\end{array}$} & F/21ys. & $\begin{array}{c}\text { Brain } \\
\text { involvement on } \\
\text { necropsy }\end{array}$ & Yes & Yes & NR & $\begin{array}{l}\text { Ampicillin/sulbac } \\
\text { tam }\end{array}$ & Died \\
\hline & F/37ys. & $\begin{array}{c}11^{\text {th }} \text { cranial nerve } \\
\text { palsy and } \\
\text { sigmoid sinus } \\
\text { thrombosis }\end{array}$ & Yes & Yes & NR & $\begin{array}{l}\text { Penicillin G and } \\
\text { Metronidazole }\end{array}$ & Recovered \\
\hline$(13) / 2005$ & M/59ys. & $\begin{array}{l}\text { Cerebral } \\
\text { infarction }\end{array}$ & Yes & No & No & $\begin{array}{l}\text { Panipenem/ } \\
\text { betamipron and } \\
\text { Clindamycin }\end{array}$ & Recovered \\
\hline$(12) / 2006$ & F/18ys. & $\begin{array}{c}6^{\text {th }} \text { and } 12^{\text {th }} \\
\text { cranial nerves } \\
\text { palsies }\end{array}$ & Yes & No & No & $\begin{array}{l}\text { Penicillin G and } \\
\text { Metronidazole }\end{array}$ & Recovered \\
\hline Present Case & F/20ys. & $\begin{array}{l}\text { Multiple Bilateral } \\
\text { Brain Abscesses }\end{array}$ & Yes & Yes & No & $\begin{array}{l}\text { Penicillin G and } \\
\text { Metronidazole }\end{array}$ & Recovered \\
\hline
\end{tabular}

NR: Non referred; F: female; M: male

*: Brain Abscess grew F. necrophorum

nisms of central nervous system involvement include retrograde propagation of thrombus into the cavernous or sigmoid sinuses $(7,11)$ or contiguous spread of infection. Based on the number and distribution of abscesses in the present case, we hypothesized the etiology to be a shower of arterial septic emboli, potentially arising from the visualized jugular venous clot, in association with the documented probe-patent foramen ovale. It was unclear whether the clot occurred before or after the central catheter insertion. However the catheter was in place for only 2 days which is a relatively short duration for a venous clot to develop as a complication of catheter insertion. Hence, we favor the possibility that the clot occurred before catheter placement.

One previous report of LS with cerebral infarction and brain abscess may have been associated with a right to left cardiac shunt, however none was documented and the ipsilateral location suggests the possibility of contiguous extension (13). In a report by Eykyn, one of 45 cases described was associated with multiple brain abscesses; however no further details were given (7). Three more cases have been 
reported in the pediatric literature describing brain abscesses as a complication of $F$. necrophorum (14-16). Vohra et al (17) reported LS with systemic emboli including brain, lungs, spleen, liver and kidney discovered on necropsy.

We describe a woman who presented with "a rare presentation of a rare disease". The initial symptoms included a purpuric rash from septic emboli, confirmed by the skin biopsy culture, pneumonia and septic shock, all of which raised the suspicion of complicated endocarditis. However, the hidden history of the preceding sore throat and the isolation of Fusobacterium necrophorum trigger the possibility of LS despite the absence of neck signs on presentation. In fact a paucity of neck signs and symptoms with LS is not uncommon, as reported by Chirinos et al (4), with $47.7 \%$ of cases presenting without significant neck findings. In the present case, the lung lesions of variable sizes and different lobar distribution are more suggestive of hematogenous septic emboli rather than lung abscess due to aspiration. These lung findings were classic and have been frequently reported in such patients but in the present case, the presence of widespread "systemic" emboli diffusely involving both cere- bral hemispheres and the peripheral emboli to the foot suggested an arterial hematogenous spread through a cardiac source. In particular, the brain lesions suggested a shower of emboli- again favoring an arterial source. This was confirmed by the contrast echocardiography which demonstrated the presence of probe-patent foramen ovale. We hypothesize that the extensive pulmonary emboli with concurrent pleural effusions caused acute pulmonary hypertension which lead to a right to left shunt opening the probe-patent foramen ovale and leading to paradoxical systemic emboli. To our knowledge this is the only adult case in the literature to document the presence of patent foramen ovale leading to systemic emboli with LS.

We report this rare case to increase clinician awareness of this "forgotten disease" for which early diagnosis and appropriate antibiotic therapy are associated with a favorable outcome and low mortality (4). Of concern, the number of LS cases may increase, including those complicated by cardiac shunt, as practitioners are encouraged to avoid excessive antimicrobial therapy when dealing with upper respiratory tract infections.

\section{References}

1. Lemierre A. On certain septicemias due to anaerobic organisms. Lancet 1: 701-703, 1936.

2. Syed MI, Baring D, Addidle M, Murray C, Adams C. Lemierre syndrome: two cases and a review. Laryngoscope 117: 1605-1610, 2007.

3. Sinave CP, Hardy GJ, Fardy PW. The Lemierre syndrome: suppurative thrombophlebitis of the internal jugular vein secondary to oropharyngeal infection. Medicine (Baltimore) 68: 85-94, 1989.

4. Chirinos JA, Lichtstein DM, Garcia J, Tamariz LJ. The evolution of Lemierre syndrome: report of 2 cases and review of the literature. Medicine 81: 458-465, 2002.

5. Carlson ER, Bergamo DF, Coccia CT. Lemierre's syndrome: two cases of a forgotten disease. J Oral Maxillofac Surg 52: 74-78, 1994.

6. Beldman TF, Teunisse HA, Schouten TJ. Septic arthritis of the hip by Fusobacterium necrophorum after tonsillectomy: a form of Lemierre syndrome?. Eur J Pediatr 156: 856-857, 1997.

7. Eykyn SJ. Necrobacillosis. Scand J Infect Dis Suppl 62: 41-46, 1989.

8. Bader-Meunier B, Pinto G, Tardieu M, Pariente D, Bobin S, Dommergues JP. Mastoiditis, meningitis and venous sinus thrombosis caused by Fusobacterium necrophorum. Eur J Pediatr 153: 339 341, 1994.

9. Larsen PD, Chartrand SA, Adickes ED. Fusobacterium necrophorum meningitis associated with cerebral vessel thrombosis. Pediatr
Infect Dis J 16: 330-331, 1997.

10. Vogel LC, Boyer KM. Metastatic complications of Fusobacterium necrophorum sepsis. Two cases of Lemierre's postanginal septicemia. Am J Dis Child 134: 356-358, 1980.

11. Agarwal R, Arunachalam PS, Bosman DA. Lemierre's syndrome: a complication of acute oropharyngitis. J Laryngol Otol 114: 545$547,2000$.

12. Jones C, Siva TM, Seymour FK, O'Reilly BJ. Lemierre's syndrome presenting with peritonsillar abscess and VIth cranial nerve palsy. J Laryngol Otol 120: 502-504, 2006.

13. Shibasaki Warabi Y, Yoshikawa H, Idezuka J, Yamazaki M, Onishi Y. Cerebral infarctions and brain abscess due to Lemierre syndrome. Intern Med 44: 653-656, 2005.

14. de Rautlin de la Roy Y, Toma V, Grignon B, Grollier G, Paute MC. Cerebral abscess due to Fusobacterium necrophorum. Importance of the conditions of the sample and of the bacteriologic analysis. Nouv Presse Med 7: 3454-3455, 1978 (in French).

15. Rathore MH, Barton LL, Dunkle LM. The spectrum of fusobacterial infections in children. Pediatr Infect Dis J 9: 505-508, 1990.

16. Meis JF, Polder TW, van de Kar P. Hoogkamp-Korstanje JA. Multiple brain abscesses and bacteremia in a child due to Fusobacterium necrophorum. Infection 21: 174-176, 1993.

17. Vohra A, Saiz E, Ratzan KR. A young woman with a sore throat, septicaemia, and respiratory failure. Lancet 350: 928, 1997.

(C) 2010 The Japanese Society of Internal Medicine http://www.naika.or.jp/imindex.html 